\title{
Dual addictions, parallel treatments: nicotine replacement therapy for patients receiving methadone treatment in the Islamic Republic of Iran
}

\author{
G. Heydari, ${ }^{7}$ F. Talischi, ${ }^{7}$ E. Batmanghelidj, ${ }^{2}$ M.R. Pajooh, ${ }^{3}$ A. Boroomand, ${ }^{7}$ M. Zamani, ${ }^{3}$ A. Salehi ${ }^{3}$ and S. Maddah ${ }^{4}$
}

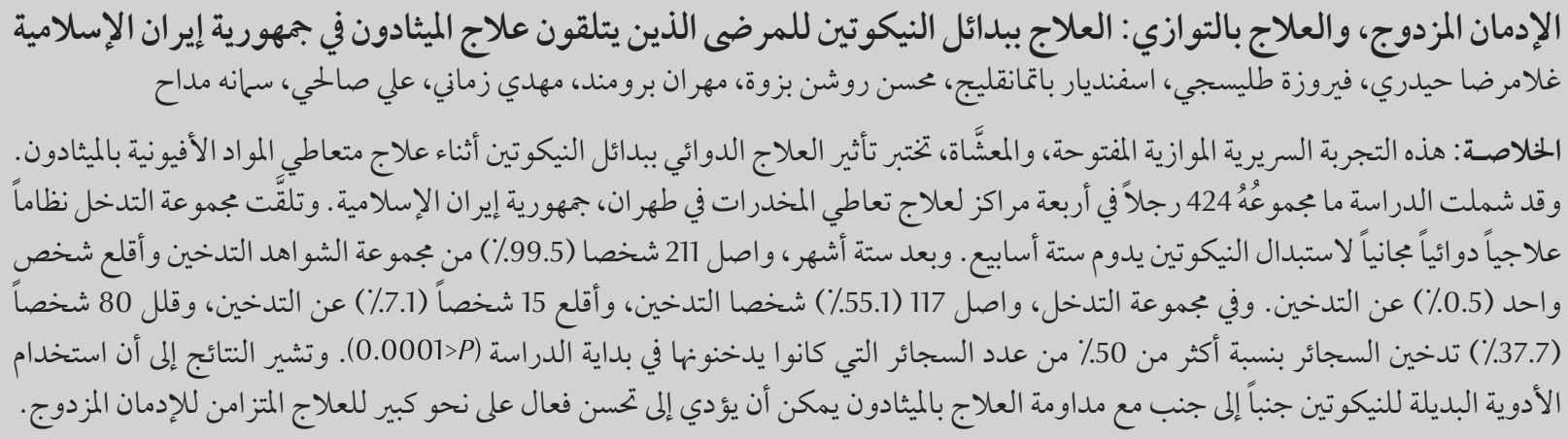

ABSTRACT This parallel, randomized, open-ended clinical trial tested the impact of nicotine replacement pharmacotherapy during the course of methadone treatment among opiate abusers. A total of 424 men entered the study at 4 drug treatment centres in Tehran, Islamic Republic of Iran. The intervention group received a 6-week regimen of nicotine replacement pharmacotherapy at no charge. After 6 months, 211 persons (99.5\%) in the control group continued to smoke and 1 person (0.5\%) had quit. In the intervention group, 117 (55.1\%) persons smoked, $15(7.1 \%)$ persons had quit and $80(37.7 \%)$ had reduced by more than $50 \%$ the number of cigarettes they smoked at the start of the study $(P<0.0001)$. The findings suggest that the use of nicotine replacement pharmacology in tandem with methadone maintenance treatment can lead to dramatically improved efficacy for treatment of dual addictions.

Co-addictions et traitements concomitants : traitement de substitution à la nicotine chez des patients traités par méthadone en République islamique d'République islamique d'Iran

RÉSUMÉ Le présent essai clinique ouvert, randomisé, en deux groupes parallèles, visait à tester les effets du traitement de substitution nicotinique chez des consommateurs d'opiacées sous traitement à la méthadone. Pour cette étude, 424 hommes au total ont été recrutés dans quatre centres de prise en charge des toxicomanies, à Téhéran (République islamique d'Iran). Le groupe faisant l'objet d'une intervention a reçu un traitement de substitution nicotinique d'une durée de six semaines bénéficiant d'une prise en charge totale. Dans le groupe témoin, 211 personnes $(99,5 \%)$ continuaient à fumer après six mois et une personne $(0,5 \%)$ avait arrêté. Dans le groupe ayant bénéficié de l'intervention, 117 hommes (55,1\%) étaient toujours fumeurs, 15 (7,1\%) avaient cessé de fumer et $80(37,7 \%)$ avaient réduit leur consommation de plus de moitié par rapport au nombre de cigarettes qu'ils fumaient au début de l'étude $(P<0,0001)$. Les conclusions semblent indiquer que I'utilisation couplée du traitement de substitution nicotinique et du traitement d'entretien à la méthadone peut améliorer considérablement l'efficacité pour le traitement des co-addictions.

${ }^{7}$ Tobacco Prevention and Control Research Center, National Research Institute of Tuberculosis and Lung Diseases, Shahid Beheshti University of Medical Sciences, Tehran, Islamic Republic of Iran.

${ }^{2}$ Meliora Health Corporation, Vienna, Virginia, United States of America (Correspondence to E. Batmanghelidj:yar.batmanghelidj@gmail.com). ${ }^{3}$ Welfare Organization, Tehran, Islamic Republic of Iran.

${ }^{4}$ Armaghan Behbood Iranian, Tehran, Islamic Republic of Iran.

Received: 10/10/2012 accepted: 04/02/2013 


\section{Introduction}

Unlike narcotics abuse, which exhibits immediate detrimental health effects, the negative health effects of smoking may take years and even decades to appear [1]. Nicotine addiction is rarely regarded with the same urgency as drug narcotics abuse in the scope of public health. Yet, with the rise of cigarette consumption within developing countries reaching epidemic levels, the spectre of widespread smoking-related morbidity and mortality remains a looming public health crisis [2]. It is predicted that by 2030 over $80 \%$ of smoking-related deaths worldwide will occur in countries with low or average income [3].

In the Islamic Republic of Iran, a high smoking prevalence has emerged as a significant risk to public health. Conservative estimates place the overall prevalence at $16 \%$ [4]. Recent data show that $80.6 \%$ of current smokers first experimented before the age of 15 years (around the average age of narcotics experimentation). It is estimated that $10.3 \%$ of young people smoke habitually [5]. Trends indicate that young people in the Islamic Republic of Iran are experimenting with tobacco more frequently and at younger ages. Over the past two decades the demographics of drug abuse in the Islamic Republic of Iran have been similarly changing. Whereas the average age of addiction used to fall between 25 and 29 years, that figure is now between 10 and 19 years [6]. Today, the average drug abuser is younger and less financially stable. Couple this trend with an overall younger population in the Islamic Republic of Iran (two thirds of Iranians are below the age of 30 years) and the number of drug abusers is burgeoning. The behavioural connections between smoking and drug use become important as the mean age of introduction for tobacco and narcotics converge.

The intersection of these "dual addictions" is particularly problematic for Iranian health officials. Tobacco usage is very common among those addicted to drugs and especially among opiate abusers, who constitute the majority of the Islamic Republic of Iran's addict population. Among this group 60\%$90 \%$ are smokers [7]. This phenomenon of dual addictions has been noted in studies around the world. In a study conducted in the north-eastern United States of America, $83 \%$ of those who receive methadone treatment are also addicted to smoking cigarettes [8]. Data from China's National Institute of Addiction show that cigarette smoking is prevalent among an astounding $99.4 \%$ of opiate addicts [9]. The principle explanation for the high prevalence of nicotine addiction among opium addicts is the neurochemical relatedness of the addictions. Research has shown that nicotine addiction is controlled by the same chemical nerve receptors that control addiction to opium derivatives [10]. Those undergoing methadone treatment report an intensified craving for nicotine [11]. Stein et al. [12, 13] conducted a series of experiments in 2006 and 2007 that suggest there is a significant relationship between nicotine replacement therapy and a reduction in both smoking and drug abuse. Reid et al. in 2008 [14] demonstrated that smoking cessation treatment can be added to treatment for drug abuse. Elkader et al. in 2009 [15] showed that those who quit smoking cigarettes become more jovial and less restless or depressed and suggested that the two treatments can be combined. Contrarily, Wapf et al. noted that many treatment personnel wilfully tolerate nicotine addiction among their patients as they see smoking as a coping mechanism for patients struggling with cravings for heroin and other hard drugs [11].

Overall, the question of whether nicotine replacement therapy and drug abuse interventions can be successfully combined merits further study. Nonetheless, it is clear that the elimination of nicotine dependency is crucial for the successful treatment of drug addiction.
Doctors, clinicians and public health experts should become aware of the relationship between addiction to nicotine and opium derivatives in order to better provide for the social costs of public health. This research paper represents the first evidence from within the Islamic Republic of Iran in support of parallel treatment of dual addictions.

\section{Methods}

\section{Study design and sampling method}

This was a balanced randomized (1:1 ratio between intervention and control), parallel group study conducted across four drug treatment centres in Tehran, Islamic Republic of Iran. The study was registered at the Islamic Republic of Iran's Trial Registration Centre under code IRCT138901111878N1 and took place during the period between December 2010 and September 2011, under the direction of the Centre for Research on Prevention and Control of Tobacco, Shahid Beheshti University of Medical Sciences. Registration required written consent from subjects. Drug addicts who had been referred to one of four targeted drug abuse treatment centres in order to undergo methadone maintenance treatment were chosen as the sample population for this study.

Eligibility requirements included a history of drug abuse, including the use of opiates such as opium and heroin, hashish, recreational drugs or others narcotics, for at least 1 year prior to referral to the drug treatment centre. In addition, inclusion was conditional upon at least 1 year of habitual tobacco consumption, in the form of cigarettes or hookah. Subjects were removed from the study if they exhibited mental or physical illness that could have affected outcomes.

Four urban centres for drug abuse treatment affiliated with the Tehran Welfare Organization, the Medical Sciences University of Tehran and Shahid 
Beheshti University were chosen at random for this multicentre trial. These treatment clinics were Shahid Mellatdoost, Mehr Ayeen, Payam Salamat and Khaneh Roshan. At these centres, patients were provided with 5-10 mg of methadone syrup twice a day, as their regimen required. In order to carry out the intervention treatment in the designated centres, doctors and attending clinicians were given a 3-day theoretical training course plus a 1-week practical training course and began work after an evaluation process.

By utilizing the formula for sample size $n \geq[Z 1-\alpha / 2+Z 1-\beta] 2$ (P1(1-P1) $+\mathrm{P} 2(1-\mathrm{P} 2)\} /$ (P1-P2) 2 and assuming that after 6 months $15 \%$ of the intervention group and $5 \%$ of the control group manage to quit smoking, and considering $\alpha=0.05$ at up to the power of $80 \%$, the minimum required sample size in each group was determined to be 144 . Furthermore, assuming that $30 \%$ of the study population would drop out of the study and factoring the additions that would then be made, a total of 178 people were needed to participate in each group.

\section{Smoking cessation treatment}

Both intervention and control groups were provided with behavioural therapy to aid in smoking cessation. The behavioural therapy employed was in line with the clinical practice guidelines suggested by the Office of the Surgeon General of the United States of America in the report Treating tobacco use and dependence: 2008 update [16]. Behavioural therapy involves gauging the patient's degree of cigarette dependence and counselling as to the nature of nicotine addiction, the negative health consequences of smoking and the possible tactics for quit attempts. This method involves employing the "five As" model. Clinicians first ask about tobacco use, advise their patients to quit, assess willingness to make a quit attempt, assist in the quit attempt by providing counselling, medication and encouragement, and finally arrange a follow-up. While subjects in both intervention and control groups were provided therapy in line with this model, only the intervention group was provided with the requisite medication in the form of a 6-week, Novartismanufactured nicotine replacement therapy regimen, which consisted of step-down 30-mg, 20-mg and 10-mg nicotine patches, and a supply of 4-mg chewing gum and 1-mg pills.

This additional pharmacotherapy, which distinguishes the intervention from the control, was administered in accordance with the clinical practice guidelines, which have come to explicitly note the improved outcomes obtainable through pharmacological aids. Subjects were provided with a 1-week supply of nicotine replacement therapy in order to manage cravings throughout the day in accordance with the instruction of clinicians. The nicotine replacement therapy pharmacotherapy was provided free of charge by Meliora Health Corporation.

\section{Measuring results}

Outcomes were evaluated in a manner consistent with the primary aims of the "Russell Standard" [17]. During the period of the trial, self-reportage of both drug abuse and smoking reductions and abstinence was tabulated. While subjects would first be encouraged to self-report abstinence from smoking and drug abuse, at both 1 and 6 months (end-point at 6 months, RS6), outcomes of treatment were blindly measured through biochemical verification (carbon monoxide exhalation test). Measuring at 1 -month gauges the initial impact of the pharmacological intervention, while the 6-month followup tests robustness of treatment in the long term. Drug treatment success was concurrently determined with the use of a rapid methadone-opiates-amphetamines test and thin-layer chromatography at both the 1-month and 6-month stages.
Although weaning individuals off methadone dependence is the ultimate goal in any drug treatment programme, the first priority is to supplant drug addiction by providing a safe alternative in a clinical setting. Subjects were therefore monitored for relapse in drug abuse during the course of methadone treatment, an event known as "slippage". Drug treatment success was defined as the total absence of illicit abuse, even if the subject remained heavily dependent on methadone. A reduction in smoking was defined as a greater than $50 \%$ reduction in cigarettes smoked per day when compared with the initial severity of the habit. The primary end-point of efficacy in this trial for parallel treatment was complete cessation of nicotine addiction, or "giving up the habit", with the secondary end-point being the prevention of slippage into drug abuse during the course of methadone treatment.

\section{Data survey}

Data were processed and analysed using SPSS, version 11 software. Relative frequency of variables was determined and compared using the $t$-test and chisquared test with a significance level of $P \leq 0.05$.

\section{Ethical issues}

Patients' consent was gained before initializing the study and assurance was given for the confidentiality of their information with an emphasis that no names or addresses would be mentioned. They were also assured that the study had no physical or mental consequences. The study was approved by a review panel of the Iran Clinical Trial Registration Centre, which requires compliance with stringent ethical guidelines.

\section{Results}

As seen in Figure 1, during the period from December 2010 to September 2011, a total of 485 men were referred 
to the centres for drug abuse and were considered for inclusion in the study.

However, 36 (7.2\%) did not qualify to participate. Out of the 449 remaining candidates, 25 (5.5\%) were not willing to undergo smoking cessation treatment. The remaining 424 persons were assigned in a simple randomization process into intervention and control groups using a computergenerated list of random numbers. The researchers then informed clinicians as to the type of treatment to administer to assigned subjects. Clinicians were not blind to the inclusion of subjects in either the intervention or control groups at the point at which treatment was administered.

The minimum age was 15 years and maximum age was 88 years, with an average 43.9 [standard deviation (SD) 13.5]. With regards to educational attainment, 122 (28.8\%) participants had not received a high school diploma, 131 (30.9\%) had received a high school diploma and 171 (40.3\%) had received higher certificates.

Concerning marital status, 56 persons (13.2\%) were single, $306(72.2 \%)$ were married, 40 (9.4\%) were separated, $11(2.6 \%)$ were divorced and $11(2.6 \%)$ were widowers. As for employment, 45 persons $(10.6 \%)$ were unemployed, 265 (62.5\%) had short-term work or were self-employed, 89 (21\%) were civil servants, 13 (3.1\%) were retired and $12(2.8 \%)$ were students.

Regarding the number of cigarettes smoked daily, 86 persons (20.3\%) smoked less than 10 cigarettes, 141 (33.3\%) smoked between 11 and 20 cigarettes, 114 (26.9\%) smoked between 21 and 30 cigarettes and 83 (19.6\%) smoked more than 30 cigarettes per day. The intensity of nicotine dependence was measured using the Fagerstrom test. A minimum score of 0 points and a maximum of 10 points was observed, with the average score being 5.3 (SD 2.7) points. Subjects had a minimum of 2 years and a maximum

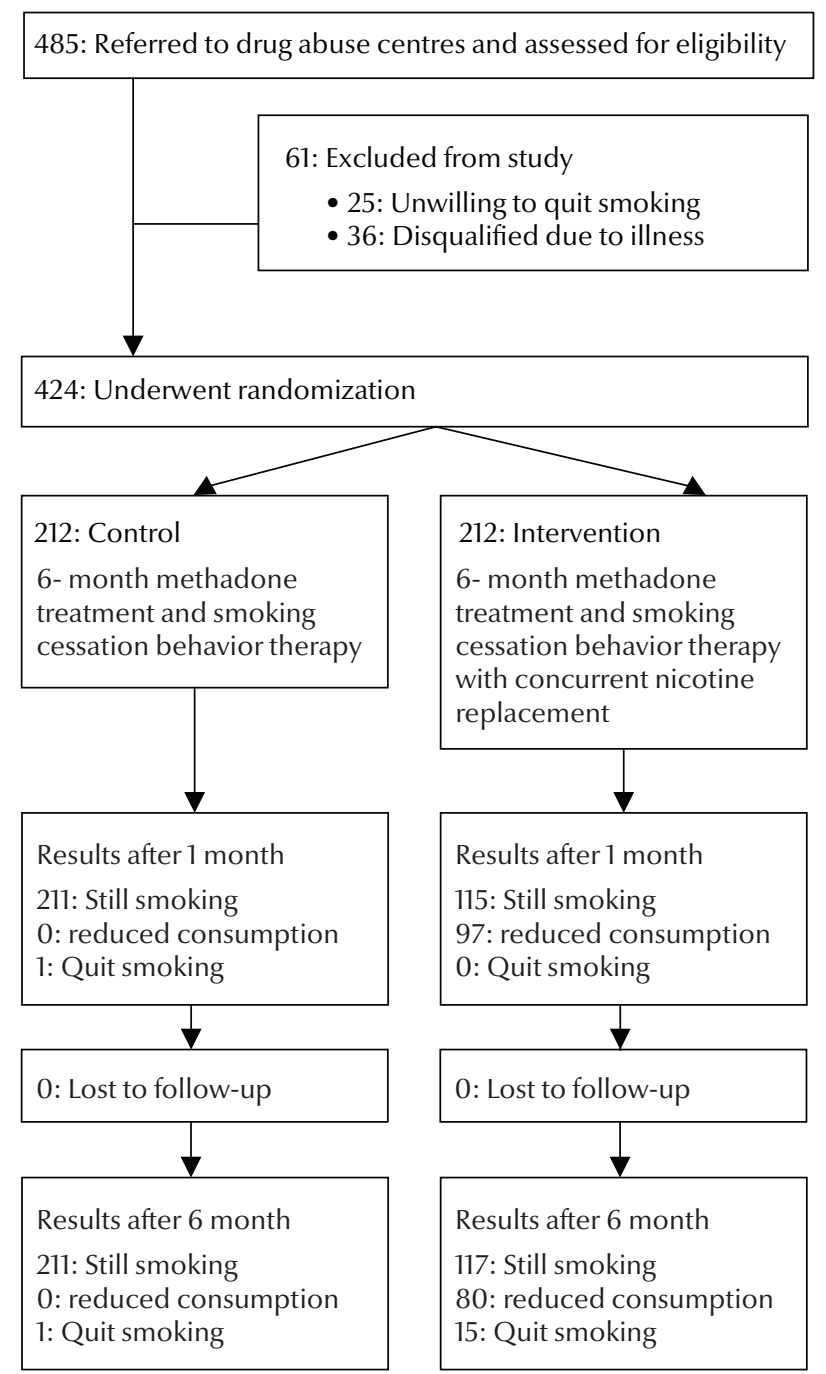

Figure1 Implementation process of the clinical trial.

of 60 years engaged in the habitual consumption of cigarettes, with an average of 22.1 (SD 11.3) years. Two hundred participants (47.2\%) had made previous attempts to quit smoking.

The minimum number of years of drug abuse was less than 1 year. The maximum number of years of drug abuse was 55 years, with an average of 11.3 (SD 11.7) years. Records indicated that 170 persons (40.1\%) used opium exclusively and 254 persons (59.9\%) used opium concurrently with at least one other drug. The average number of drug abuse treatment attempts was 1.6 (SD 1.2), with a minimum of 0 and a maximum of 5 attempts. Demographic specifications and the smoking and drug habits in both intervention and control groups were determined by the chi-square test and $t$-test, as shown in Table 1.

From the results obtained from Table 1 there were no significant differences between the intervention group (which received nicotine replacement therapy) and the control group (without the nicotine replacement therapy) that would have unduly influenced outcomes.

As seen in Table 2, after a period of 1 month, 197 persons in the control group (92.9\%) continued to smoke cigarettes. While no one had given up the habit, 15 persons $(7.1 \%)$ had significantly reduced their smoking consumption 


\begin{tabular}{|c|c|c|c|}
\hline Variable & Intervention group & Control group & $P$-value* \\
\hline Age (years) [mean (SD)] & $12.1(42.9)$ & $13.1(44.9)$ & 0.44 \\
\hline \multicolumn{4}{|l|}{ Education } \\
\hline Under diploma (\%) & 24.5 & 33.0 & \multirow{3}{*}{0.13} \\
\hline Diploma (\%) & 31.6 & 30.2 & \\
\hline Higher diploma (\%) & 43.9 & 36.8 & \\
\hline \multicolumn{4}{|l|}{ Marital status } \\
\hline Single (\%) & 11.3 & 15.1 & \multirow{3}{*}{0.31} \\
\hline Married (\%) & 74.5 & 69.8 & \\
\hline Separated (\%) & 14.1 & 15.1 & \\
\hline \multicolumn{4}{|l|}{ Employment } \\
\hline Self-employed (\%) & 63.2 & 61.8 & \multirow{3}{*}{0.81} \\
\hline Governmental (\%) & 21.2 & 20.8 & \\
\hline Other (\%) & 6.6 & 5.2 & \\
\hline \multicolumn{4}{|l|}{ No. cigarettes daily } \\
\hline$<10(\%)$ & 22.2 & 18.4 & \multirow{4}{*}{0.58} \\
\hline $11-20(\%)$ & 32.5 & 34 & \\
\hline $21-30(\%)$ & 27.8 & 25.9 & \\
\hline$>30(\%)$ & 17.5 & 21.7 & \\
\hline Fagerstrom test number & 5.6 & 4.9 & 0.91 \\
\hline Years smoking [mean (SD)] & $11.1(21.7)$ & $11.4(22.5)$ & 0.58 \\
\hline Years drug consumption [mean (SD)] & $10.9(17.4)$ & $11.4(18.2)$ & 0.43 \\
\hline History of quitting smoking (\%) & 50.9 & 43.4 & 0.14 \\
\hline \multicolumn{4}{|l|}{ Drug consumption } \\
\hline Only opium (\%) & 43.4 & 36.8 & \multirow{2}{*}{0.19} \\
\hline Opium and other drugs (\%) & 56.6 & 63.2 & \\
\hline No previous drug cure (\%) & $1.2(1.5)$ & $1.4(1.6)$ & 0.14 \\
\hline
\end{tabular}

*Significance level $P \leq 0.05$.

$S D=$ standard deviation

(measured as a reduction of 50\% or more). In the intervention group, 115 persons (54.2\%) continued to smoke, no one had given up the habit and 97 persons (45.8\%) had reduced their consumption of cigarettes $(P<0.0001)$.

As seen in Table 3, after 6 months, 211 persons $(99.5 \%)$ in the control group continued to smoke cigarettes and one person $(0.5 \%)$ had given up the habit. In the intervention group, 117 persons $(55.1 \%)$ continued to smoke, 80 persons (37.7\%) had reduced their cigarette consumption and 15 persons (7.1\%) had given up the habit $(P<0.0001)$. Regarding lapses back into smoking during the course of treatment, in the control group there were 13 cases $(6.1 \%)$ and in the intervention group there were three cases $(1.4 \%)$ $(P=0.019)$ as can be seen in Table 4.

This mirrors the recurrence of drug use, as there were two cases $(0.9 \%)$ in the control group and no cases $(0.0 \%)$

\begin{tabular}{lcccc}
\hline Table 2 Relative frequency of cigarette consumption in the intervention and control groups after 1 month & Total \\
\hline Group & $\begin{array}{c}\text { Cigarette } \\
\text { consumption }\end{array}$ & Quit & Reduced & No. (\%) \\
Intervention & No. (\%) & No. (\%) $(\%)$ & $97(45.8)$ & $212(100)$ \\
Control & $115(54.2)$ & 0 & $15(7.1)$ & $212(100)$ \\
Total & $197(92.9)$ & 0 & $112(26.4)$ & $424(100)$ \\
\hline
\end{tabular}

$P<0.0001$. 


\begin{tabular}{|c|c|c|c|c|}
\hline \multirow[t]{2}{*}{ Group } & $\begin{array}{c}\text { Cigarette } \\
\text { consumption }\end{array}$ & Quit & Reduced & Total \\
\hline & No. (\%) & No. (\%) & No. (\%) & No. (\%) \\
\hline Intervention & 117 (55.1) & $15(7.1)$ & 80 (37.7) & 212 (100) \\
\hline Control & 211 (99.5) & $1(0.5)$ & 0 & 212 (100) \\
\hline Total & $328(77.3)$ & $16(3.8)$ & 80 (18.8) & $424(100)$ \\
\hline
\end{tabular}

$P<0.0001$.

in the intervention group $(P=0.134)$. All subjects in both intervention and control groups continued to use methadone maintenance treatment at the 6-month stage.

\section{Discussion}

There was a strong desire among addicts in this study to undergo parallel smoking cessation treatment while undergoing treatment for drug abuse. Impressively, $95 \%$ of subjects voiced satisfaction with the additional smoking cessation therapy they received. This satisfaction also helps explain how, remarkably, no subjects were lost to follow-up. Of the 424 patients who underwent randomization, all were accounted for at the 6-month review. Moreover, doctors and staff at these centres welcomed the implementation of this therapy, as conditions were suitable for simultaneous parallel provision of both treatments. Richter and Arnsten made reference to this point in their 2008 study, noting that doctors and clinicians in recent years were increasingly supportive of the treatment of nicotine addiction among their patient populations [18]. In addition, Wapf et al. [11] have suggested that greater engagement of nicotine addiction by case managers and treatment professionals, as well as improved psychotherapeutic interventions for those struggling with smoking, might warrant the broader implementation of dual treatment programmes. On the basis of the above suggestions, providing free access to smoking cessation treatment, which in this study includes both counselling and nicotine reduction therapy (a well-rounded psychotherapeutic combination), may have been integral to achieving positive outcomes.

Several trends that emerged in the data are worth noting. Among the sample population, the average number of years of drug abuse was determined to be 4 years lower than the average number of years smoking. This is an indication that precedence in smoking cigarettes could leave individuals predisposed to more significant drug abuse at a later date. There has been an indication of this phenomenon in other studies conducted outside the Islamic Republic of Iran [19,20].

As well established in the evidence, smoking cigarettes can lead to incapacity, illnesses and premature death. These health risks are of even greater

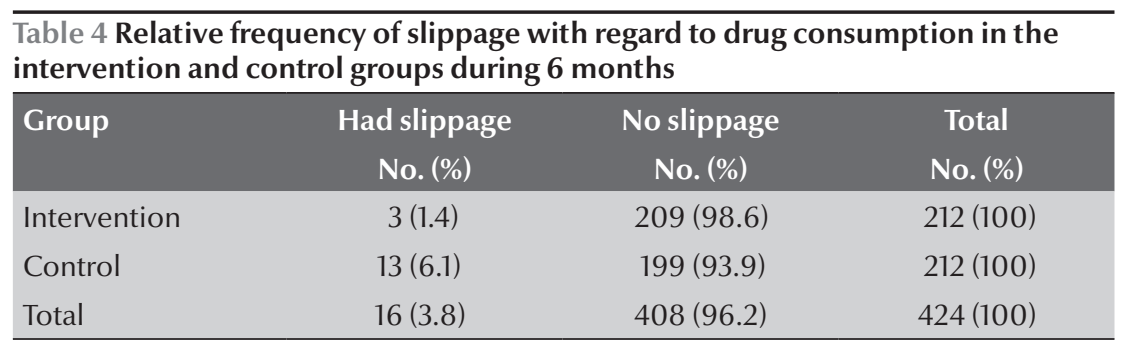

$P=0.019$. 
with only $7.1 \%$ of persons in the control group having accomplished the same. After 6 months, this rate was readjusted to $37.7 \%$ in the intervention group and $0 \%$ in the control group. It is very likely that with a longer period of smoking cessation therapy, the results could be even further improved, with the more obstinate smokers weaned off nicotine.

A related point to consider in this study is the reduction in slippage - the recurrence of drug abuse - in the intervention group over a 6-month period. While 13 persons $(6.1 \%)$ in the control group experienced slippage in drug abuse, only three persons (1.4\%) in the intervention group had similar failings.
Similar patterns have been reported in other studies [20]. This is a reassuring finding in that the effects of nicotine replacement therapy treatments tend to be robust and last months after the termination of pharmacotherapy.

In conclusion, offering smoking cessation programmes, including both clinical behavioural therapy and nicotine replacement therapy, as an integral part of methadone maintenance treatment can have a significant impact on the general health of drug abusers. Overall, parallel treatments for dual addictions are advisable as a way to reduce the possibility of failure in the complementary treatment. This study offers an initial glimpse into the potential benefits of nicotine replacement therapy as a tool in the fight against drug abuse but is limited in its scope. Extending the nicotine replacement therapy treatment duration to 12 weeks, while also including female participants into such studies, may elucidate further information. Additional research is needed to better understand the neurochemical relationship between nicotine and opiate addictions and to aid in the development of clinical practice guidelines for parallel treatment. In the Islamic Republic of Iran and other countries around the world, such research, if acted upon, could provide a crucial bulwark against a rising tide of addiction.

Competing interests: None declared.

\section{References}

1. Gilead S. Is smoking delay smoking averted? American Journal of Public Health, 2003, 93:412-416.

2. Mathers CD, Loncar D. Projections of global mortality and burden of disease from 2002 to 2030. PLoS Medicine, 2006, 3:e422.

3. Petro R et al. Mortality from smoking worldwide. British Medical Bulletin, 1996, 52:12-21.

4. Mokri, A. Brief overview of drug abuse status in Iran. Archives of Iranian Medicine, 2002, 5:184-190.

5. Ziaaddini H, Meymandi MS, Zarezadeh AR. The prevalence and motivation of cigarette smoking among Kerman high school students. Iranian Journal of Psychiatry, 2007, 2:41-45.

6. Samii W. Drug abuse: Iran's thorniest problem. Brown Journal of World Affairs, 2003, 9:283-299.

7. Bao Y, Lian Z, Liu Z. An investigation of cigarette smoking behavior and nicotine dependence among Chinese opiate addicts. Addictive Behaviors, 2009, 34:955-958.

8. Mello $\mathrm{N}$ et al. Effects of heroin self-administration on cigarette smoking. Psychopharmacology, 1980, 67:45-52.

9. Frosch D L et al. Associations between tobacco smoking and illicit drug use among methadone-maintained opiate-dependent individuals. Experimental and Clinical Psychopharmacology, 2000, 8:97-103.

10. Story J, Stark MJ. Treating cigarette smoking in methadone maintenance clients. Journal of Psychoactive Drugs, 1991, 23:205-215.

11. Wapf $\mathrm{V}$ et al. The barriers to smoking cessation in Swiss methadone and buprenorphine-maintained patients. Harm Reduction Journal, 2008, 5:10.
12. Stein MD, Anderson BJ, Niaura R. Smoking cessation patterns in methadone-maintained smokers. Nicotine \& Tobacco Research, 2007, 9:421-428.

13. Stein MD, Anderson BJ, Niaura R. Nicotine replacement therapy: patterns of use after a quit attempt among methadonemaintained smokers. Journal of General Internal Medicine, 2006, 21:753-757.

14. Reid MS et al. Smoking cessation treatment in communitybased substance abuse rehabilitation programs. Journal Substance Abuse Treatment, 2008, 35:68-77.

15. Elkader AK et al. Methadone-nicotine interactions in methadone maintenance treatment patients. Journal of Clinical Psychopharmacology, 2009, 29:231-238.

16. West $\mathrm{R}$ et al. Outcome criteria in smoking cessation trials: proposal for a common standard. Addiction, 2005, 100:299-303.

17. Fiore MC et al. Treating tobacco use and dependence: 2008 update. Clinical Practice Guideline. Rockville, MD, United States Department of Health and Human Services, Public Health Service, 2008.

18. Richter KP, Arnsten JH. A rationale and model for addressing tobacco dependence in substance abuse treatment. Substance Abuse, Treatment, Prevention and Policy, 2006, 1:23.

19. Shoptaw $\mathrm{S}$ et al. Smoking cessation in methadone maintenance. Addiction, 2002, 97:1317-1328.

20. Tacke $U$ et al. The effect of tobacco smoking on subjective symptoms of inadequacy ("not holding") of methadone dose among opiate addicts in methadone maintenance treatment. Addiction Biology, 2001, 6:137-145. 